\title{
Avoidance conditioning following preadaptation to weak shock
}

ROBERT ADAMSON, PETER HENKE, and DENIS O'DONOVAN, Florida Atlantic University, Boca Raton, Fla. 33432

Four groups of rats were preadapted, respectively, to no-shock, $.004 \mathrm{~mA}, .008 \mathrm{~mA}$, and $.02 \mathrm{~mA}$, before being conditioned in a jump box to $.03 \mathrm{~mA}$ shock preceded by a bell CS. Both the .004-mA and the .008-mA groups required significantly fewer trials $(p<.01)$ to criterion than the other two groups. The results were related to those of studies using subliminal anchor stimuli with human Ss and were interpreted in an adaptation-level framework.

Black \& Bevan (1960) and Bevan \& Pritchard (1963), using electric shock and auditory stimuli, showed that stimuli conventionally defined as subthreshold exerted an effect on S's subsequent reactions to stronger stimuli on the same continua. Their interpretation of these findings was in terms of a pooling model; that is, $\mathrm{S}$ integrated such stimulus values, however weak, into a norm (or adaptation level) which served as a referent for further stimulation.

The present study attempted to provide further evidence of the effectiveness of very weak stimulation upon behavior. Additionally, since a pooling model was involved, the study utilized rats as $S s$ in an attempt to generalize the findings referenced above. Although those studies introduced weak stimuli as anchors in a category rating task, the present study used a preadaptation paradigm instead. Black, Adamson, \& Bevan (1961) have shown that rats react differentially to a common shock reinforcer in a runway task, as a function of preadaptation to different shock intensities, and, using human Ss, Murray \& Kohfeld (1965) have shown that reaction time to a common tone signal changes as a result of preadaptation to different intensity tones. One infers a functional similarity between anchor and preadaptation effects.

The designation of a stimulus as "subthreshold" is attended by many caveats; accordingly, it is left to the reader in this case. Two preadaptive shock values were used: In neither case, were the Es able to discern any differences in behavior relative to a no-shock control. A third value was clearly above threshold and was included to check on the possibility that preadaptation simply sensitized the animal.

\section{METHOD}

Subjects were 32 male Holtzman rats, approximately 250 days old at the start of this study. Four control groups $(N=4)$ were used for threshold testing in a jump box divided by a 2-in. fence. One of the groups received no shock, while the other three received, respectively, $.004 \mathrm{~mA}, .008 \mathrm{~mA}$, and $.02 \mathrm{~mA}$. The shocks were delivered through a scrambler to the grid from a Lafayette A615 shock generator. All currents were measured with a Weston AC microammeter in series with the grid and a $100 \mathrm{~K}$ ohm resistor.

Individual Ss were placed in the box for a 20-min period, with shock applied to whichever side of the box the $S$ happened to be in (except for the no-shock group). Two counts were taken; number of crossings and defecations. There were no differences between the no-shock and the .004-mA and $.008-\mathrm{mA}$ groups on the basis of these measures, or with reference to any other aspects of their overt behavior. The $.02-\mathrm{mA}$ group, on the other hand, showed aversion to the shock, dancing and crossing the fence each time shock was administered.

The remaining 16 Ss were divided into four groups $(N=4)$ for avoidance conditioning following differential preadaptation to shock. The US was .03-mA shock for all groups. Preceding each trial, a partition was inserted to prevent fence crossing, and the Ss received $10 \mathrm{sec}$ of preadaptation at the four different values (including no-shock) used in threshold testing. At the end of this period, the partition was withdrawn, a buzzer sounded for $3 \mathrm{sec}$, during which there was no shock, and then the test shock was delivered. It stayed on until the animal crossed. This procedure was repeated for each $S$ until he had reached criterion. Intervals between trials were $20 \mathrm{sec}$.

The conditioning measure used was the number of trials to an arbitrary criterion of 12 correct out of the last 15 correct trials (those on which $S$ avoided shock).

In summary, conditions were the same for all Ss, except for the magnitude of shock during preadaptation.

\section{RESULTS}

Mean trials to criterion for the four groups were as follows: for the no-shock group, 50.5 ; for the $.004-\mathrm{mA}$ group, 22.5 ; for the .008-mA group, 22; for the .02-mA group, 37. A Kruskal-Wallis analysis of variance by ranks (1952) yielded a $\mathrm{H}$ of 16.32: $p<.01$.

The two "subliminal" groups did not differ from each other. Each, however, differed significantly from the no-shock group and from the .02-mA group. Median comparisons, using the Fisher Exact Probability Test yielded differences significant at the .014 level. The $.02-\mathrm{mA}$ group and the no-shock group had only one pair of overlapping scores. Nonetheless, this precluded statistical confirmation of a significant difference between the two groups.

\section{DISCUSSION}

The substantial differences obtained in trials to criterion support the conjecture that differential preadaptation modifies responses to a common stimulus. Thus, the results tend to confirm those obtained earlier by Black, Adamson, \& Bevan (1961) and by Murray \& Kohfeld (1965).

Additionally, if the low-shock values used in the present study are accepted as subliminal at least in terms of eliciting no observable behavioral changes, the results extend the findings of Black \& Bevan (1960) and Bevan \& Pritchard (1963) to lower organisms.

The results appear to be consistent with an adaptation-level formulation, namely, that Ss respond to a discrepancy between a stimulus norm and contemporary stimulus input. Sensitization does not appear to be an adequate interpretation of the results, since, if it were, the $.02-\mathrm{mA}$ group would be expected to be superior to the lesser shock groups. However, the possibility exists that, for this group, the buzzer interval itself may have been reinforcing. This may have lessened their tendency to jump during the interval.

If the difference between the preadaptive values and the common test shock is related to trials to criterion, a $\mathrm{U}$-shaped function is suggested, possibly reflecting tensional differences between the groups.

\section{REFERENCES}

BEVAN, W., \& PRITCHARD, J. F. The effect of subliminal tones upon the judgment of loudness. Journal of Experimental Psychology, 1963, 66, 23-29.

BLACK, R., ADAMSON, R., BEVAN, W. Runway behavior as a function of apparent intensity of shock. Journal of Comparative \& Physiological Psychology, 1961, 54, 270-274. 
on the combined frequencies of Groups 1 and 3 and Groups 2 and 4. Results indicated that 21 of 24 deprived Ss selected the food goal but only 13 of 24 satiated Ss did so $\left(x^{2}=6.28\right.$, $\mathrm{df}=1, \mathrm{p}<.02$ ). It was decided to sum novel selections across Days 1-8 (as in Experiment 1) and study a possible interaction effect as well as the main effects produced by the food deprivation and food present-absent variables. A 2 by 2 analysis indicated greater preference for the novel goal by satiated Ss regardless of food presence or absence in the plain box $(F=84.98, d f=1 / 44, p<.01)$. Inspection of novel selections for each group during Stages 2 and 3 suggested that the food present-absent variable was of little consequence and that Groups 1 and 3 and Groups 2 and 4 could be combined without undue distortion of group trends. Fig. 2 illustrates the two curves and terminates Stage 3 after five days since the remaining 10 days presented relatively stable and redundant data. Note in both figures that the deprived Ss with food present in Stage 1 express a comparable retarded preference for novel stimuli, although the preference increases despite the fact that half the deprived $S s$ in Experiment 2 had food available during Stage 2. Also note that in Fig. 2 there is no definite shift to the food location when food is introduced in Stage 3 for half the deprived Ss and half the satiated Ss.

There were no apparent differences between satiated Ss and deprived Ss on the number of contacts with novel objects; however, this frequency did decline systematically from an average of eight contacts per $S$ on Day 1 to three contacts on Day 15 of Stage 2 . Conversely an unstable but increasing number of spontaneous alternations occurred for all groups from an estimated 19 of 40 on Day 1 to 31 of 40 possible alternations on Day 15 of Stage 2.

\section{DISCUSSION}

Despite changes in the procedure, apparatus, and preexperimental conditions of the Ss tested, Experiments 1 and 2 demonstrated a greater preference by food-satiated rats for the novel setting. The data of Experiment 1 suggested that food presence rather than food deprivation was the crucial variable since deprived Ss and satiated Ss (Groups C-2 and C-1) displayed equivalent preference behavior during Stage 2 without encountering food in Stage 1. However, food was provided for all rats in Stage 1 of Experiment 2 and then removed from half the deprived Ss and half the satiated Ss during Stage 2. Unlike Experiment 1, differences were apparent in novel selections between satiated and deprived animals indicating that food presence in Stage 1 was affecting deprived Ss more than satiated Ss.

An activity measure indexed by figurine contacts and an assessment of orderliness behavior expressed by spontaneous alternations failed to reflect differences between treatments, thereby offering support for Lester's (1967) contention that deprivation has no consistent effect on these measures of exploration. Nevertheless, Figs. 1 and 2 confirm that the deprivation variable produced a differential bias in novel selections and indicate a degree of consistency for choice behavior which should qualify as an orderliness measure.

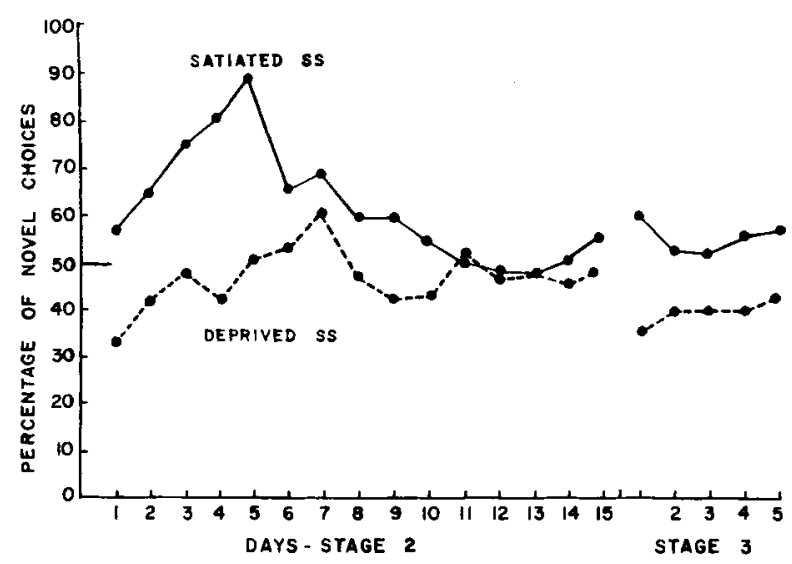

Fig. 2. The percentage of novel turns distributed across Stage 2 and five days of Stage 3 in Experiment 2.

With the exceptions noted in Figs. 1 and 2 deprived Ss and satiated Ss tended to settle into a 35 to $70 \%$ preference for the novel goal, a finding comparable to the no-preference behavior observed by Leckart \& Bennett (1968) for their food and novelty group. These authors noted that food and novelty were equal in their capacity to reinforce instrumental behavior despite the fact that their rats were food deprived but not stimulus deprived. This latter claim is questionable since their animals were maintained in individual cages (barren?) and were released daily for only one trial, a procedure which could conceivably induce stimulus deprivation by virtue of the contrast between living quarters and the test apparatus. In fact, capturing such terms as "stimulus deprivation" and "novelty" by operational definition is a difficult task. Present data revealed that as the number of figurine contacts diminished the frequency of spontaneous alternations increased, suggesting that the value of one incentive (figurines) was decreasing as the value of another incentive (?) became dominant. The food incentive is presumed to be relatively stable as long as rats are hungry but novelty values are not so durable and can be supplanted by other incentives which may or may not be associated with exploration. Thus, the relationship of preference behavior to food and novel incentives continues to be intriguing but the clarification is elusive.

\section{REFERENCES}

LECKART, B., \& BENNETT, K. Reinforcement effects of food and stimulus novelty. Psychological Record, 1968, 18, 253-260.

LESTER, D. Effects of fear upon exploratory behavior. Psychonomic Science, 1967, 9, 117-118.

TAYLOR, G. Exploratory preference behavior as a function of previously reinforced stimuli, drive level, and food presence. Unpublished Master's Thesis, Stephen F. Austin State College, 1968.

\section{(Continued from page 119)}

BLACK, R. W., \& BEVAN, W. The effect of subliminal shock upon judged intensity of weak shock. American Journal of Psychology, $1960,73,262-267$.

KRUSKAL, W. H., \& WALLIS, W. A. Use of ranks in one-criterion variance analysis. Journal of the American Statistical Association, $1952,47,583-621$.
MURRAY, H., \& KOHFELD, D. Role of AL in stimulus intensity dynamics. Psychonomic Science, 1965, 3, 439-440.

\section{NOTE}

1. This study was supported by the Air Force Office of Scientific Research, Grant No. 1163-66. 